\title{
Adalbert Mischlewski
}

\section{Soziale Aspekte der spätmittelalterlichen Antoniusverehrung}

Im Jahre 1526 erschien eine Folge von 73 Holzschnitten unter dem Titel „Das Babsttum mit seynen glidern gemalet und beschryben, gebessert und gemehrt". Sie werden Sebald Beham zugeschrieben und greifen in scharfer Form den „Babst und Antichrist“, die kirchliche Hierarchie und sämtliche Orden an. Als erster wird „Der Anthoniterorden" mit folgenden Versen vorgestellt:
„Anthoni herrn man dise nendt
In alle landt man sie wol kendt
Das macht jr stettes terminiren
Das arm volck sie schentlich verfueren
Mit trauung sanct Anthoni peyn
Bettlen sehr/auch lerns jre schweyn.
Schwartz/darauff blaw creutz ist jr kleyt
Sind all bủben schwer jch eyn eyd" (Abb. 1) ${ }^{1}$.

Zwar polemisch überzogen, aber sachlich zutreffend, werden in diesen Versen jene Phänomene genannt, welche die mittelalterliche Antoniusverehrung zu einem gesellschaftlichen Faktor machten, dem sich niemand entziehen konnte: die jährlichen Almosensammlungen der Antoniter und die Antoniusschweine. Ehe wir uns damit näher beschäftigen, soll zunächst kurz auf die Frage eingegangen werden: Wie kam es zu diesen Phänomenen, die aus dem spätmittelalterlichen Alltagsleben nicht fortzudenken sind?

Die Verehrung des Antonius Eremita spielte sich im Abendland in einem eher be-

1 Die Holzschnitte wurden nur selten publiziert, z. B. von Max Geisberg, Die Reformation in den Kampfbildern der Einblatt-Holzschnitte aus der ersten Hälfte des 16.Jahrhunderts (München 1928) III, 11; Veit Harold Bauer, Das Antonius-Feuer in Kunst und Medizin (Berlin, Heidelberg, New York 1973) 30 f. Dagegen diente der Text immer wieder zur Kennzeichnung des angeblich nur auf Erwerb materieller Güter gerichteten Wesens der Antoniter, 2. B. Johann Georg Schelhorn, Ergötzlichkeiten aus der Kirchenhistorie und Literatur, Bd. 2 (Ulm und Leipzig 1763) 606; Eugen Robling, Die Reichsstadt Memmingen in der Zeit der evangelischen Volksbewegung (München 1864) 58, Anm. 2; Otto Zöckler, Antonius-Orden, in: Realencyklopädie für protestantische Theologie und Kirche, Bd. 1 (Leipzig ${ }^{3} 1896$ ) 607; Friedrich Braun, Die Antonier und ihr Haus in Memmingen, in: Beiträge zur bayerischen Kirchengeschichte 9 (1903) 241-270, 10 (1904) 1-28, hier 9, 261, Anm. 3. 
scheidenen Rahmen ab, ehe er - mehr zufälligerweise - zu einem Krankheitspatron geworden war ${ }^{2}$. In den letzten Jahren des 11 .Jahrhunderts war in weiten Teilen Westeuropas eine Krankheit aufgetreten, die man wegen ihrer brennenden Schmerzen ignis sacer nannte; sie wurde erst im 17. Jahrhundert als Mutterkornbrand diagnostiziert. Das gepeinigte Volk suchte allenthalben Zuflucht und Hilfe bei den vertrauten Heiligen der näheren und weiteren Umgebung. Der heilige Antonius, dessen angebliche Gebeine erst nach der Mitte des 11.Jahrhunderts in ein winziges Dörfchen der Dauphiné gekommen sein sollen, das nach ihm Saint-Antoine genannt wurde, war zunächst nur einer unter einer ganzen Reihe von Helfern gegen die schreckliche Krankheit, und nicht einmal der angesehenste. Daß er schließlich alle anderen übertraf und sogar die Krankheit nach ihm ignis sancti Antonii, Antoniusfeuer, genannt wurde, war das Verdienst einiger Laien.

Da die Bauern des Dorfes und die Handvoll Mönche des dortigen Benediktinerpriorates nicht imstande waren, den Scharen der Pilger, und vor allem den Kranken unter ihnen, die notwendige Versorgung zuteil werden zu lassen, fanden sich etliche Männer und Frauen, verheiratete wie ledige, zusammen, um die notwendige Hilfe zu leisten. Aus diesem spontanen Akt christlicher Caritas sollte sich eine Bewegung entwickeln, die das ganze christliche Abendland erfaßte.

Wenn dieser in der losen Form einer Bruderschaft organisierten Gemeinschaft noch in der ersten Generation auswärtige Spitäler angeboten wurden, wenn sie noch vor Ablauf des ersten Jahrhunderts ihrer Existenz Außenstellen über den südfranzösisch-oberitalienischen Raum hinaus bis in Spanien und Deutschland geschenkt erhielt, dann läßt das bestimmte Schlüsse zu, die durch Belege aus späterer Zeit untermauert werden. Ihre Leistungen auf dem Gebiet der Hospitalorganisation und der Therapie, auch die der von ihnen angestellten Wundärzte, müssen das normale Maß erheblich überschritten haben.

Das Ausmaß und die weitreichenden Auswirkungen der Antoniusverehrung im späten Mittelalter lassen sich jedoch nicht allein aus dem Wirken und dem Renommee einer Krankenpflege- und Krankenhausträgergemeinschaft erklären. Ein weiterer wichtiger Faktor war die Angst, die - wie uns Jean Delumeau gezeigt hat - im Laufe des 14. Jahrhunderts eine neue Qualität annahm, was er wesentlich auf die Pestepidemien zurückführt. Auch die Angst vor dem Antoniusfeuer wird man nicht gering veranschlagen dürfen ${ }^{3}$. Die unheimliche und unerklärliche Krankheit tauchte immer wieder auf und forderte ihre Opfer: es starben etwa ein Drittel der Erkrankten ${ }^{4}$.

2 Zum Folgenden siehe ausführliche Darstellung mit Belegen bei Adalbert Miscbleuski. Grundzüge der Geschichte des Antoniterordens bis zum Ausgang des 15.Jahrhunderts (Bonner Beiträge zur Kirchengeschichte 8, Köln und Wien 1976), im folgenden zitiert: Miscbleuski, Grundzüge, und ders., Das Antoniusfeuer in Mittelalter und früher Neuzeit in Westeuropa, in: Maladies et Société XII ${ }^{e}-X V I I I$ e siècles. Actes du Colloque de Bielefeld novembre 1986, éd. par Neithard Bulst et Robert Delort (Paris 1989) 249-268, im folgenden zitiert Mischlewski, Antoniusfeuer.

3 Jean Delumeau, Angst im Abendland. Die Geschichte kollektiver Ängste im Europa des 14. bis 18. Jahrhunderts, Bd. 1-2 (rororo 7929, Reinbek 1985), der S. 90 das Antoniusfeuer zu den am meisten gefürchteten Krankheiten zählt.

4 Horst Wirth, Über die Mutterkornvergiftungen, in: Natur und Heimat 3 (1954) 320-324, hier 322. 
Die ständige Angst, vielleicht auch immer stärkere Lobpreisungen der Macht und der Möglichkeiten des heiligen Antonius führten zu einer bedenklichen Veränderung seines Bildes. War er ursprünglich der gütige Thaumaturg, so ist er schon kurz nach 1200 in der Biographie Hugos von Lincoln der Rächer, der jene Burgen durch Blitzschlag zerstört, deren Besitzer die Pilger nach Saint-Antoine schlecht behandelt haben ${ }^{5}$. Folgerichtig erhielt die Krankheit auch den Namen "Sankt Antonien Rache ${ }^{\text {u6 }}$. Doch damit noch nicht genug. In einem Rückfall in heidnische Vorstellungen verbanden sich mit der Gestalt des demütigen Heiligen aus der ägyptischen Wüste die furchtbaren und gewaltsamen Züge des antiken Saturn (Abb. 2 und 3)

Antonius war nun der Herr über die Krankheit, die seinen Namen trug und die er willkürlich verhängen konnte und auch verhāngte. Selbst im Kölner Festoffizium von 1500, also in einer kirchenamtlichen Quelle heißt es: „Percutit et sanat, extinguit et excitat ignes $^{\text {“8 }}$. Die sozusagen ordensoffiziellen Darstellungen des wie eine Gottheit mitten auf dem Altar thronenden Antonius, die sich in Antoniterkirchen von Bern bis Frauenburg finden', atmen einen ähnlichen Geist (Abb. 4 und 5). Von der bekanntesten, dem Isenheimer Antonius, sagt der Straßburger Kunsthistoriker Roland Recht treffend, er sitze dort in einer „terrible souveraineté ${ }^{\text {“10 }}$. Da Sankt Anton per analogiam auch der Herr über das Feuer und den gefürchteten Rotlauf der Schweine geworden war ${ }^{11}$, gab es noch mehr Grund, mit allen Mitteln den gnādig zu stimmen, der im Bewußtsein vieler nur mehr das Zerrbild eines christlichen Heiligen, nach den Worten Huizingas gar ein „böser Feuer-Dämon" war ${ }^{12}$. Nur auf diesem Hintergrund können

5 James Francis Dimock, Magna Vita S. Hugonis Episcopi Lincolniensis (Rerum Britannicarum Medii Aevi Scriptores 37, London 1864) 311.

6 Mischlewski, Antoniusfeuer, 257, Anm. 73.

7 Wolfgang Kübn, Gestalt und antike Vorbilder des Antonius Eremita, in: Psyche 2 (1948) 7196. - Zu Abbildung 3: Die Kinder des Saturn werden häufig mit amputiertem Unterschenkel dargestellt. Hier trägt einer das Tau-Zeichen auf der Brust, das ihn als einen vom Antoniter-Orden unterhaltenen Krüppel ausweist.

8 Gandulf Korte, Antonius der Einsiedler in Kult, Kunst und Brauchtum Westfalens, hrsg. von Adalbert Klaus (Werl/Westf. 1952) 29, im folgenden zitiert Korte, Antonius.

- Eine Aufstellung der bis jetzt nachgewiesenen, auf dem Altar thronenden Antoniusfiguren von Freiburg i.Br. bis Frauenburg bei Adalbert Miscblewski, Die Antoniter und Isenheim, in: Mathis Gothart Nithart Grünewald. Der Isenheimer Altar. Fotos: Max Seidel. Texte von Heinrich Geissler, Bernbard Saran, Joseph Harnest, Adalbert Miscblewski (Stuttgart 1973) 256-266, 281-288, hier 264; für Bern siehe: Die Kunstdenkmäler der Schweiz. Die Kunstdenkmäler des Kantons Bern 5 (Basel 1969) 22.

10 Roland Recht, Les sculptures du retable d'Issenheim, in: Grunewald et son œuvre. Actes de la Table Ronde organisée par le Centre National de la Recherche Scientifique à Strasbourg et Colmar du 18 au 21 octobre 1974 (Cahiers Alsaciens d'Archéologie, d'Art et d'Histoire 19-20, 1975) 27-46, hier 36.

"Hans Aurenbammer, Lexikon der christlichen Ikonographie, Bd. 1 (Wien 1959-67) 159; Elfriede Grabner, Das „Heilige Feuer", „Antoniusfeuer“, Rotlauf und „Rose“ als volkstümliche Krankheitsnamen und ihre Behandlung in der Volksmedizin, in: Österreichische Zeitschrift für Volkskunde 66 (1963) 77-95.

12 Johann Huizinga, Herbst des Mittelalters. Studien über Lebens- und Geistesformen des 14. und 15.Jahrhunderts in Frankreich und in den Niederlanden. Hrsg. von Kurt Köster (Stuttgart "1975) 241. 
die spātmittelalterliche Antoniusverehrung und ihre Auswirkungen adāquat gewürdigt werden.

Wichtigster und deutlichster Ausdruck des Antoniuskultes waren die alljährlichen Almosensammlungen der Antoniter ${ }^{13}$. Zwar konnte nicht jeder in einer Antoniuskirche oder -kapelle beten - warum diese Möglichkeiten im Laufe der Zeit eher ab- als zunahmen, wird noch zur Sprache kommen -, noch weniger war normalerweise eine Wallfahrt nach Saint-Antoine gegeben, bei den Heiltumsfahrten jedoch konnte jeder, selbst im abgelegenen Bergdorf, dem mächtigen und gewalttātigen Herm seine Reverenz erweisen.

Schon vor $1180^{14}$, also längst ehe sie ein Orden (1247) ${ }^{\text {is }}$ und eine Chorherrengemeinschaft $(1297)^{16}$ geworden waren, hatten die Antoniusbrüder damit begonnen, für ihr Spital, die Kranken und Krüppel Sammlungen außerhalb ihrer näheren Umgebung zu veranstalten, da die eigenen Ressourcen für die immer größer werdenden Verpflichtungen nicht mehr ausreichten. Der Quest der Antoniter wurde im Laufe der Zeit immer mehr ausgebaut und seit Innozenz IV. (1243-1254) ${ }^{17}$ von den Päpsten wieder und wieder dringend empfohlen. Die alljährliche Ankunft der nuntii sancti Antonii war ein besonderer Tag für die ganze Gemeinde, der selbst zur Zeit eines eventuellen Interdikts wie ein Sonntag begangen wurde. Klerus und Volk zogen mit Kreuz und Fahnen und unter Glockengeläut dem Antoniusboten entgegen, der in der Kirche den Gottesdienst hielt. Er predigte über die „miracula sancti Anthonii et verbum Dei“ - man beachte die Reihenfolge! -, wobei er nicht versāumte, auf die caritativen Leistungen in den gegen Ende des 15. Jahrhunderts über 370 Antoniterhospitãlern hinzuweisen. Nachdem er mit den Antoniusreliquien den Segen erteilt hatte (Abb. 6), nahm er die Gaben entgegen, zumeist Münzen, aber auch Naturalien. Als

$13 \mathrm{Vgl}$. zum Folgenden Einzelheiten und Belege bei Jakob Rauch, Die Almosenfahrten der Höchster Antoniter am Ausgang des Mittelalters, in: Archiv für mittelrheinische Kirchengeschichte 2 (1950) 163-174; Albrecht Eckhardt, Almosensammlungen der Grünberger Antoniter zwischen Mittelgebirge und Nordsee. Mit einem Beitrag zur Identifizierung des Bruderschaftsbuches in Bremen, in: Archiv für hessische Geschichte und Altertumskunde N.F. 32 (1974) 113 160; Miscblewski, Grundzüge, 273-292; ders., Die Auseinandersetzung des Nikolaus von Kues mit den Antonitern, in: Innsbrucker Historische Studien 9 (1986) 19-36, hier $20 \mathrm{f}$., im folgenden zitiert Miscblewski, Nikolaus von Kues. - Den Text einer Sammelpredigt siehe jetzt bei Adalbert Miscblewski, Eine deutsche Antoniterpredigt aus dem 15. Jahrhundert, in: Hubert Mordek (Hrsg.), Aus Archiven und Bibliotheken. Studien zum Recht und zur Kirchengeschichte des Mittelalters. Festschrift Raymund Kottje (Frankfurt/Main 1992) 477-488.

14 Aymarus Falco, Antonianae historiae compendium ex variis iisdemque gravissimis ecclesiasticis scriptoribus, necnon rerum gestarum monumentis collectum, una cum externis rebus quam-

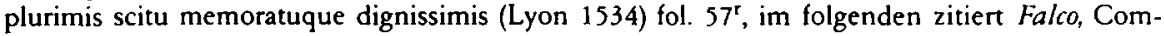
pendium.

is Mischleuski, Grundzüge, 46.

16 Miscblewski, Grundzüge, 63-65; erst vollständige Publikation der Gründungsbulle: 358-364.

171245 II 21: Empfehlung und Privilegierung der Sammlungen der Antoniusbrüder (Les Registres d'Innocent IV publiés ou analysés d'après les manuscrits originaux du Vatican et de la Bibliothèque Nationale par Elie Beryer, T. 1 (Paris 1884) 182, Nr. 1174); 1245 III 1: Ermahnung, ihre Predigt und Sammlung nicht zu behindern (ebd., 187, Nr. 1201). Das päpstliche Privileg wurde also nicht erst unter Clemens IV. (1265-1268) erteilt, wie Rauch, Almosenfahrten, 163 meint. Auch Eckbardt, Almosensammlungen, 116f. kennt das Datum der Bulle nicht. 
Gegengabe verteilte er Glöckchen, die oft als Schutz für die Tiere im Stall angebracht wurden; für die größeren Wohltäter gab es Handschuhe und Messer mit dem Taukreuz. So war die Erinnerung an den Orden des heiligen Antonius und seinen Patron ständig präsent. Nach dem Gottesdienst wurden noch die Weiler und Einzelhöfe besucht, wobei die Antoniter das Privileg genossen, ihr Kommen durch eine Handschelle zu avisieren. Diese Glocke wurde eines der Attribute des Heiligen und vom Orden als Privileg erbittert gegen Konkurrenten verteidigt ${ }^{18}$; erst 1481 konnte der Heilig-Geist-Orden von Sixtus IV. (1471-1484) die gleiche Vergünstigung erlangen ${ }^{19}$. Um zu den Wohltātern ein festes Band zu knüpfen, hatten die Antoniter ebenfalls schon sehr früh Bruderschaften ins Leben gerufen - um 1200 sind sie bereits eine Selbstverstāndlichkeit ${ }^{20}$. Die Mitglieder, Männer und Frauen, verpflichteten sich zu einer festen jährlichen Abgabe und hatten dafür Anteil an allen „Gebeten, Messen, Fasten, Nachtwachen und Almosen " des Ordens. Weitere Privilegien waren neben relativ geringen Ablässen, christliches Begräbnis während eines Interdikts und, seit 1486, zweimal im Jahr freie Wahl eines Beichtvaters, der von allen Sünden und Strafen absolvieren konnte, ausgenommen die päpstlichen Reservatfälle. Ferner konnte er alle Gelübde in gute Werke umwandeln, außer jene, eine Wallfahrt nach Jerusalem, Rom oder Santiago zu unternehmen, in einen Orden einzutreten oder in vollkommener Keuschheit zu leben. Geistlichen und Ordensleuten war darüber hinaus Vergebung für unterlassenes Stundengebet zugesagt. Die freilich umstrittene Praxis des Beichthörens wird manchen Bauern, die sonst nur auf ihren Pfarrer angewiesen waren, nicht unangenehm gewesen sein.

Spenden für den Antoniusboten, besser noch Mitgliedschaft in der Antoniusbruderschaft, war für die meisten mehr als ein religiöser und caritativer Akt. Es wurde schon deutlich, wie wichtig es bei dem vorherrschenden Antoniusbild war, diesen

181388 I 31: im Streit zwischen dem Isenheimer Präzeptor und dem Heilig-Geist-Spital in Rufach wegen des Sammelns mit Glocken ergeht ein Urteil des Basler Offizials zu Gunsten des ersteren (Memmingen, Stiftungsarchiv, 220/1; 1394 XI 20: der Meister des Heilig-Geist-Spitals in Memmingen verzichtet in einem gütlichen Vergleich mit den Antonitern auf den weiteren Gebrauch der Glocken beim Almosensammeln (Memmingen, Stiftungsarchiv, 222/1). Besonders hartnăckige Konkurrenten scheinen auch die Almosensammler des St. Valentinshospitals für Epileptiker in Rufach gewesen zu sein (vgl. hierzu Médard Barth, Das St.-Valentinus-Heiligtum in Rufach, sein Ruf in der deutschsprachigen Welt und seine Sonderstellung unter den Almosen heischenden Spitälern, in: Heiltumführer und Almosensammler des Mittelalters, in: Freiburger Diözesan-Archiv 74 (1954) 100-131, hier 103-111, im folgenden zitiert: Barth, Heiltumführer). 1399 VII 12: die Isenheimer Antoniter gewinnen einen Prozeß gegen die Rufacher Valentinsbrüder wegen des Sammelns mit Glocken vor dem Offizial in Straßburg, 1406 III 17: der Augsburger Bischof verbietet (wohl auf Betreiben der Memminger Antoniusbrüder) derm gleichen Spital den Gebrauch der Schelle (beide Urkunden Memmingen, Stiftungsarchiv 220/1).

19 Pietro de Angelis, L'Ospedale apostolico di Santo Spirito in Saxia nella mente e nel cuore dei papi (Collana di studi storici sull'ospedale di Santo Spirito in Saxia e sugli ospedali Romani 16, Roma 1956) 74; im folgenden zitiert De Angelis, Santo Spirito.

${ }^{20} \mathrm{Zu}$ den Antoniusbruderschaften siehe Pieter Noordeloos, Enige gegevens over broederschappen van S. Antonius, in: Publications de la Société historique et archéologique dans le Limbourg 85 (1949) 477-499, im folgenden zitiert Noordeloos, Broederschappen, der freilich den ältesten Nachweis um fast ein Jahrhundert zu spät ansetzt, vgl. dazu Mischlewski, Nikolaus von Kues, $21 \mathrm{f}$. 
unberechenbaren Herrn über Menschen- und Tierkrankheiten und sogar über das Element des Feuers günstig zu stimmen. Andere Möglichkeiten dazu gab es, wenn überhaupt, nur selten, war es doch den Antonitern dank päpstlicher Unterstützung in einmaliger Weise gelungen, die Verehrung eines Heiligen zu monopolisieren ${ }^{21}$. Beginnend mit Urban IV. (1261-1264), der 1262 anordnete, daß alle dem heiligen Antonius gemachten Gelübde und Versprechungen nur dem Antoniushospital in der Vienner Diözese einzulösen seien, über Bonifaz VIII. (1294-1303), der 1298 verbot, an ordensfremden Antoniusgotteshāusern Antoniusschweine zu halten, führt in gerader Linie zu Johannes XXII. (1316-1334), der 1330 die Errichtung von Antoniusaltären und -kapellen überhaupt verbot, da sie immer wieder zum Vorwand für Almosensammlungen zu Ehren des Heiligen genommen würden. Da der Antoniterorden es erfolgreich verstanden hat, dieses einzigartige Privileg auch in die Wirklichkeit umzusetzen, wie z. B. in Hoppingen (LK Nördlingen), wo 1365 an und in der dortigen Kapelle alle Antoniusbilder und -zeichen getilgt werden mußten, gab es für die Gläubigen häufig keine andere Möglichkeit der Antoniusverehrung als die von den Antonitern selbst angebotene. Auf diese Weise ergab sich immer auch eine soziale Rückversicherung, da ja jedermann ständig in der Gefahr stand, vom Antoniusfeuer befallen zu werden, worunter man mangels Kenntnis des Kausalnexus auch den relativ häufigen Wundbrand verstand $^{22}$. Im Falle der Erkrankung am ignis sancti Antonii oder nach Gliederverlust infolge dieser Krankheit hatte jedermann Anspruch, in ein Antoniterspital (Abb. 7) aufgenommen zu werden, allerdings nur unter der Voraussetzung, daß er nachweisen konnte, wāhrend der Krankheit den heiligen Antonius angerufen zu haben ${ }^{23}$, was naturgemäß sehr schwierig sein mußte, bei Bruderschaftsmitgliedern jedoch als sicher angenommen werden konnte.

Betrachtet man alle diese Aspekte, so erscheint es nicht verwunderlich, daß der Quest der Antoniter zunächst ausgesprochen beliebt war. Das änderte sich erst mit der Inflation der jährlichen Almosensammlungen. Seit dem 14. Jahrhundert kamen ständig neue hinzu, so daß die sogenannten „vier Botschaften“" (nach Regionen wechselnde Sammlungen, zu denen aber immer die statio sancti Antonii gehörte) ${ }^{24}$ oft nur ein Minimum darstellten. Der fränkische Ritter Michael von Ehenheim war mit seiner

${ }^{21}$ Zur Monopolisierung der Antoniusverehrung und den Folgen siehe Miscbletwski, Grundzüge, $89 \mathrm{f}$.

22 Miscblewski, Grundzüge, 350.

23 In den Reformstatuten von 1478, die indes viele ältere Regeln enthalten, heißt es: „quod omnes ... personae ... infirmae praefato morbo seu igne gehennali vulgariter ... nuncupato igne $S$. Antonii, quae siquidem personae eorum durante infirmitate praedicta ad monasterium vel domos ... ipsius ordinis recursum habuerint pro beati Antonii suffragiis implorandis et observandis selt alias ipsum beatum Antonius in eorum infirmitate bumiliter et devote invocare et ad ipsitus merita recursum babuerint, in ... hospitali, ad quod applicuerint, ... recipi debeant ..." (Zitiert nach Höchst, Verein für Geschichte und Altertumskunde, Liber Statutorum Monasterii Ordinis Sancti Antonii Viennensis, fol. $215^{\mathrm{v}} \mathrm{f}$., im folgenden zitiert: Liber Statutorum. Hervorhebung vom Autor).

${ }^{24}$ Ludwig Andreas Veit, Volksfrommes Brauchtum und Kirche im Mittelalter (Freiburg i. Br. 1936) 42; Barth, Heiltumführer, $102 \mathrm{f}$. 
Ehefrau um 1515 Mitglied in nicht weniger als sieben Bruderschaften, darunter in der des heiligen Antonius mit dem geringsten Beitrag von jährlich 6 Pfennigen ${ }^{25}$.

Hatte sich in früheren Zeiten die Kritik an den Sammelfahrten der Antoniter daran entzündet, daß man die Echtheit der vorgezeigten Reliquien bezweifelte, und war dieser Zweifel allem Anschein nach auf Intellektuelle wie Giovanni Boccaccio (1313 bis $1375)^{26}$ und Niccolò de Tudeschis (1386-1445) ${ }^{27}$ beschränkt, so gewann sie im Laufe des 15.Jahrhunderts andere Dimensionen. Die in wirtschaftlich schlechten Zeiten besonders spürbare Belastung des gemeinen Volkes “ und das Bestreben der Territorialherren, das Geld im Lande zu behalten ${ }^{28}$, die z.T. wohl beabsichtigte, größtenteils aber sicher nicht direkt intendierte Drohung mit dem rächenden Antonius ${ }^{29}$ und schließlich die angesichts des Reichtums des Ordens verstāndliche Befürchtung, daß das gesammelte Geld gar nicht oder nur zum Teil für die „armen dorfftigen “ verwendet würde ${ }^{30}$, alle diese Faktoren erschwerten schon vor der Reformation ${ }^{31}$ die Antoniussammlungen. Selbst kirchliche Autoritāten wie Nikolaus von Kues, Bischof von Brixen seit $1450^{32}$, und das Augsburger Domkapitel (zwischen 1513 und

25 Ludwig Remling, Bruderschaften in Franken (Quellen und Forschungen zur Geschichte des Bistums und Hochstifts Würzburg 35, Würzburg 1986) 60.

${ }_{26}$ Giovanni di Boccaccio, Decamerone, 6. Tag, 10. Geschichte: einer von den Mönchen des hl. Antonius will Bauern eine Feder des Engels Gabriel zeigen. Als ihm zwei Burschen diese Feder durch Kohlen ersetzen, gibt er diese als Kohlen aus, mit denen der hl. Laurentius geröstet worden sei.

27 Niccolò de Tudeschis, erwāhnt in einem Dekretalenkommentar ${ }_{n}$ clericos qui causa questus decipiunt populum fingendo religuias ubi non sunt, et maxime in hoc errant isti questuarii sancti Antonii" (zitiert nach Hubert Silvestre, Commerce et vol de reliques au moyen age, in: Revue belge de philologie et d'histoire 30 (1952) 721-739, hier 728, A. 6).

${ }^{28}$ In den Gravamina der deutschen Nation auf dem Wormser Reichstag 1521, „die nicht unmittelbar im Zusammenhang mit dem Auftreten Luthers (causa fidei) standen" (Heribert Raab, Gra-

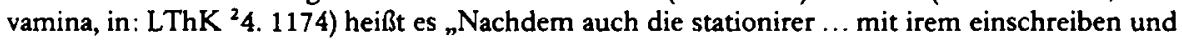
bettlerei vil gelts von den leuten bringen ... solichs dermassen nit mer zu gestatten. Dann etwan ist sanct Anthonius bottschaft allain umbgezogen, jetzo kummen darzu des Heiligen Gaists, sanct Hauprechts, sanct Cornelius und sanct Velten ect. gesannten, dardurch das gemain, ainfeltig volk mit behendigkait umb sein barschaft betöret wurdt" (Adolf Wrede (Bearb.), Deutsche Reichstagsakten, Jüngere Reihe 2 (Gotha 1896) $678 \mathrm{f}$,, ähnlich 685 , im folgenden zitiert: Wrede, RTA).

${ }^{29}$ Hiergegen polemisierten sowohl Erasmus in seinen Colloquia (1519) (Opera omnia Desiderii Erasmi Roterodami, Ordinis primi Tomus tertius, ed. Léon-Eernest Halkin, Franz Bierlaire, René Hoven (Amsterdam 1972) 691) wie auch die Gravamina (Wrede, RTA, 685).

3o So schon die Reformatio Sigismundi (Heinrich Koller, Reformation Kaiser Siegmunds (MGH, Staatsschriften des späteren Mittelalters 6, Stuttgart 1964) 350), spāter auch der Entwurf einer Polizeiordnung auf dem Reichstag zu Worms 1521 ( Wrede, RTA, 360). Die Behauptung von den zweckentfremdeten Geldern findet sich schon bei Guiot de Provins kurz nach 1200 (John Orr, Les œuvres de Guiot de Provins, poète lyrique et satirique (Manchester 1915) 71, im folgenden zitiert: Orr, Guiot de Provins).

${ }^{31}$ Die gegenteilige Meinung (z. B. Anton Störmann, Die städtischen Gravamina gegen den Klerus am Ausgange des Mittelalters und in der Reformationszeit (Reformationsgeschichtliche Studien und Texte 24-26, Münster 1916 61) bedarf der Differenzierung. Es scheint vielmehr, als habe die Lehre der Reformatoren einem verbreiteten Unbehagen nur die theologische Argumentation geliefert.

${ }^{32}$ Miscblewski, Nikolaus von Kues, $25 \mathrm{f}$. 
$1517)^{33}$ erlegten den Antoniusboten starke Einschränkungen auf oder erteilten überhaupt keine Sammelerlaubnis mehr.

Waren es auf dem Lande mehr die Almosensammlungen mit den verteilten Gegenständen, die den heiligen Antonius, seinen Orden und seine Mārtyrer, wie die Kranken genannt wurden, immer wieder in Erinnerung riefen, so in den Städten mehr die Antoniusschweine ${ }^{34}$. Sie waren um 1200 bereits weit verbreitet ${ }^{35}$. Wer nichts oder nur wenig spenden konnte, übergab häufig eines der neugeworfenen Ferkel - Raffinierte wählten das schwächste oder kränklichste ${ }^{36}$ - an den zuständigen Antoniter, der es mit einem Glöckchen und mit dem Ordenszeichen Tau, der stilisierten Krücke der Krüppel, versah (Abb. 8 und 9). In Zukunft wurde es von der Allgemeinheit genährt, hāufig von Abfällen. Wenn es großgezogen war, erhielt es der Orden, eventuell auch nur die geräucherten Schinken oder den Verkaufserlös. Naturgemāß mußten die frei herumlaufenden Schweine in den Städten mehr auffallen als auf dem Lande, zumal es dem Antoniterorden gelungen war, sich seit Clemens IV. (1265-1268) auch auf diesem Gebiet die päpstliche Privilegierung und dauernde Protektion zu sichern ${ }^{37}$. Obwohl die in der Stadt frei umherlaufenden Schweine Anlaß zu tödlichen Unfällen von Kindern ${ }^{38}$ und Erwachsenen ${ }^{39}$ wurden und trotz der immer strenger werdenden $\mathrm{Hy}$ gienevorschriften der Städte gelang es den Antonitern, sich ihre kostenlose Reklame bis zur Reformationszeit zu erhalten. Nur ein so māchtiges und selbstbewußtes Gemeinwesen wie die Serenissima konnte es wagen, 1409 die Antoniusschweine generell

${ }^{33}$ Konzept eines Beschwerdebriefes des Memminger Präzeptors Caspar von Leutzenpron (im Amt seit 1513), geschrieben vor 1517 (Memmingen, Stadtarchiv 356/4).

34 Eine wissenschaftliche Monographie fehlt. Vgl. Mischlewski, Grundzüge, $36 \mathrm{f}$.

33 Orr, Guiot de Provins, 71.

36 So tadelt z. B. Geiler von Kaysersberg: „Oder hast du ein lahmes Ferkel, das finnig ist: es ist eben recht, sprichst du, ich will es St. Antönchen verehren" (Luzian Pfleger. Kirchengeschichte der Stadt Straßburg im Mittelalter (Kolmar 1941) 215).

${ }^{37} 1265$ IV 22 (Les Registres de Clément IV (1265-1268). Recueil des Bulles de ce Pape publiées ou analysées d'après les manuscrits originaux des Archives du Vatican par M. Edouard Jordan (Paris 1945) 469, Nr. 1554).

38 1322 V 19: eine umherlaufende Sau beißt in London einen Säugling im Alter von einem Monat zu Tode (Perry Flemming, Notes on St. Anthony the Great, in: The Archaeological Journal 89 (1932) 79-86, hier 83).

39 1131 X 13: Philippe, der bereits zum König gesalbte Erstgeborene Ludwigs VI. stürzt in einem Pariser Außenbezirk mit seinem Pferd, das ein Schwein zum Straucheln gebracht hat, und stirbt nach wenigen Stunden (Suger, Vie de Louis VI le Gros, éditée et traduite par Henri Waquet (Les classiques de l'histoire de France au moyen âge 11, Paris $\left.{ }^{2} 1964\right)$ 266; Léon Mirot. La chronique de Morigny (1095-1152) (Collection de textes pour servir à l'étude et à l'enseignement $\mathrm{d}$ l'histoire 41, Paris 1909) 55; Hercule Géraud, Chronique latine de Guillaume de Nangis de 1113 à 1300 (Paris 1843) 22). Ordericus Vitalis gibt im Liber XIII seiner Historia ecclesiastica, „eine(r) der wichtigsten Quellen für 1125-1140“ (Hans Wolter, Ordericus Vitalis, in: LThK ${ }^{27}$, 1208), als Grund für den Unfall an, der Thronfolger habe im Spiel einen Knappen durch die Straßen gejagt (The Ecclesiastical History of Ordericus Vitalis 6, Books XI, XII, and XIII, ed. and transl. by Mar. jorie Chibnall (Oxford 1978) 420f). Achille Luchaire, Louis VI le Gros. Annales de sa vie et de son règne (1081-1137) (Paris 1890) 219, Nr. 474, erwähnt überhaupt keine Ursache. 
zu verbieten ${ }^{40}$. Dagegen duldete Lübeck 1465 noch $20^{41}$, Bamberg $1481^{\text {t2 }}$ und Würzburg $1502^{43}$ je 6, München 1475 nur noch 4 Stück $^{44}$. Unhaltbar wurde die Situation erst, als seit Sixtus IV. (1471-1484) auch der Heilig-Geist-Orden, der schärfste Konkurrent der Antoniter, diese bequeme Art, lukrative Einnahmen zu erzielen, imitieren durfte ${ }^{45}$. Schon vor dem großen Umbruch des 16 . Jahrhunderts war das vor allem in den Stādten auffallende lebende Markenzeichen der Antoniter obsolet geworden.

Erst verhāltnismäßig spät wird auch der Adel als Stand in das Kultsystem der Antoniter miteinbezogen. Es ist auffallend, mit welcher Stārke die Antoniusverehrung in den beiden letzten Jahrhunderten des Mittelalters bei den Edelleuten Gestalt gewinnt, bis hinauf in den Fürstenstand. Die Herrscher von Mailand ${ }^{\mathbf{4 6}}$ und Ferrara ${ }^{\mathbf{4 7}}$, die Herzöge von Burgund ${ }^{48}$, Ludwig XI. ${ }^{49}$ und Kaiser Siegmund ${ }^{50}$ seien nur als die hervorragendsten unter ihnen genannt. Gandulf Korte hat in seiner 1952 erschienenen Geschichte des Antoniuskultes in Westfalen eindrucksvoll zeigen können, in welchem Ausmaß der westfälische Adel im Verlaufe des 14. und 15. Jahrhunderts seine Burgund Schloßkapellen oder wenigstens einzelne Altāre unter das Patronat des heiligen Antonius stellte. Er vermutet sicher zu Recht, daß weniger dessen vornehme Abkunft, sondern mehr sein tapferer Kampf gegen die Versuchungen und Angriffe des Teufels

40 1409 X 10: Beschluß des Gran Consilio (Giuseppe Tassini, Curiositá veneziane ovvero origine delle denominazioni stradali di Venezia (Venezia o.J.) 35).

41 Lübecker UB 10 (Lübeck 1898) 601, Nr. 190.

42 Georg Thomas Rudhart, Die Sanct Anthonier-Schweine in Bamberg, in: Taschenbuch für vaterländische Geschichte 39 (1850) $302 \mathrm{f}$.

43 Würzburg, Staatsarchiv, Rößner-Buch 863, fol. $129^{\mathrm{v}}$.

44 Michael Schattenbofer, Die „Rennsau“, in : Münchner Stadtanzeiger vom 29.5.1964, S. 7.

45 Die päpstliche Genehmigung wurde erteilt mit der Bulle „Alto Divinae providentiae“ vom 8. Juni 1481 (de Angelis, Santo Spirito, 74).

46 Gian Galeazzo Visconti (1351-1402), seit 1395 Herzog von Mailand, stiftete im Kloster SaintAntoine eine Chorherrenpfründe und eine tāgliche Messe. Darüber hinaus ließ er für den 1237 von den übrigen Gebeinen abgetrennten Armknochen ein Reliquiar aus purem Gold anfertigen und sorgte für die Ausmalung der "Chapelle du Saint-Bras“ (Falco, Compendium fol. 85 ). Seine Nachfolger Filippo Maria (1402-1447), Francesco Sforza (1450-1466) und Galeazzo Sforza (1466-1476) erzeigten dem Kloster Saint-Antoine ebenfalls ihre besondere Munifizenz (ibid., fol. $93^{\mathrm{r}}, 94^{\mathrm{v}}, 97^{\mathrm{T}}$ ). Kein Wunder, daß der Herzog von Mailand zu den vier Privilegierten gehörte, die bei der feierlichen Prozession am Himmelfahrtstag den Antoniusschrein tragen durften (Hippolyte Dijon, L'église abbatiale de Saint-Antoine en Dauphiné (Grenoble, Paris 1902) 334), wozu er normalerweise selbstverständlich Vertreter entsandte (Falco, Compendium, fol. 937).

$47 \mathrm{Zu}$ den engen Beziehungen der Markgrafen, seit 1471 Herzöge von Ferrara zum Kloster und Orden des hl. Antonius siehe Adalbert Mischlewski, Jean d'Orlier und die Umgestaltung der Antoniterkirche in Isenheim, in: Le retable d'Issenheim et la sculpture au nord des Alpes à la fin du Moyen Age, Actes du colloque de Colmar (2-3 novembre 1987) (Colmar 1989) 122-127.

48 Über die Antoniusverehrung Philipps II., Herzog von Burgund (1363-1404), siehe Mischlewski, Grundzüge, 101.

49 Mischlewski, Grundzüge, 318.

so Mischlewski, Grundzüge, 135, 153; dazu Regesta Imperii 11. Sigismund von Luxemburg: 1410-1437. Bearbeitet von Wilhelm Alimann, 1. Band (Innsbruck 1896) 117, Nr. 1794, 193, Nr. 2715,230, Nr. 3246, 233, Nr. 3293. 
ihn, den „bellicosum contra daemones virum“, zu einem Vorbild ritterlicher Gesinnung werden ließen ${ }^{51}$.

Mitglieder der seit dem 12. Jahrhundert bestehenden Antoniusbruderschaften waren alle Gesellschaftsschichten, auch Fürsten und Adlige ${ }^{52}$; die besondere Pflege des Antoniuskultes durch den Adel sowie dessen Streben nach deutlicher Unterscheidung von den anderen Ständen führten im 15. Jahrhundert zur Gründung rein adliger Antoniusbruderschaften. Der Anfang wurde im Hennegau gemacht. Gérard d'Enghien, Herr von Havré bei Mons, hatte 1402 zusammen mit etlichen anderen Rittern beschlossen, an einer von ihm gestifteten Antoniuskapelle in Barbefosse eine ritterliche Konfraternitāt zu errichten ${ }^{53}$. Auch hier beharrten die Antoniter erfolgreich auf ihrem Monopol des Antoniuskultes und gründeten 1415 in Barbefosse eine Präzeptorei, der die Bruderschaft angeschlossen werden mußte ${ }^{54}$.

Aufgenommen wurden gemäß den Statuten von 1420 nur Adlige, auch Frauen, "sans reproche“; die Aufnahmegebühr war nach dem Rang gestaffelt und reichte von 6 Franken für einen Schildknappen bis zu 96 Franken für einen Doppelbannerherrn $^{55}$. Die erhalten gebliebene Mitgliederrolle für die Jahre 1415 bis 1438 enthält 376 Namen adliger Herkunft, zumeist aus den vom Hause Wittelsbach regierten Grafschaften Hennegau, Seeland und Holland; aber auch etliche Ritterbürtige vom Niederrhein, vereinzelt sogar aus dem übrigen Reich und aus England, sind vertreten ${ }^{56}$. In einer Zeit, da immer neue Ritterorden gegründet wurden, gab sich auch die adlige Bruderschaft die Form eines Ordens. Daher wurde ein eigenes markantes Zeichen geschaffen. Es bestand aus einem Kollier, einer schmucklosen Kette, an der eine Potence hing, wie das Tauzeichen im Antoniterorden genannt wurde, an der wiederum ein Glöckchen befestigt war. Für Ritter und deren Gattinnen war das Bruderschaftszeichen vergoldet, Knappen und ihre Ehefrauen trugen es in Silber ${ }^{57}$. Bei dem bekannten Bildnis des Mannes mit der Nelke, das Jan van Eyck zugeschrieben wird (Abb. 10), hätten wir es demnach mit einem Edelknappen aus der Antoniusbruderschaft von Barbefosse zu tun. Das Bruderschaftszeichen mußte nach dem Tod des Trägers wieder am Sitz der Gemeinschaft abgeliefert werden ${ }^{58}$.

Das große Echo, das die Gründung der ersten ritterlichen Antoniusbruderschaft gefunden hatte, ließ einen fürstlichen Verehrer des Mönchsvaters und Adelspatrons nicht ruhen. Herzog Adolf II. von Kleve (1394-1448), aus dessen Landen mindestens zehn Ritterbürtige Angehörige der Konfraternität im Hennegau waren ${ }^{59}$, entschloß sich, ebenfalls eine adlige Antoniusbruderschaft für Männer und Frauen zu errichten. Auch hier folgte, genau wie etliche Jahre zuvor in Barbefosse, dem Entschluß zur

51 Korte, Antonius, 21-23.

52 Miscblewski, Nikolaus von Kues, 32 f.

${ }_{53}$ Noordeloos, Broederschappen, 487.

54 Ibid., 492.

53 Ibid. die Statuten von 1420: 494-497, hier 495. Vgl. auch Anm. 73.

56 Friedrich Gorissen, Der klevische Ritterorden vom hl. Antonius, in: Kalender für das Klever Land auf das Jahr 1963, 29-49, hier 33 f., im folgenden zitiert: Gorissen, Ritterorden.

57 Noordeloos, Broederschappen, 494.

58 Ibid., 495.

59 Gorissen, Ritterorden, 33. 
Gründung (1420) die Errichtung einer Antoniterpräzeptorei auf dem Hau, unmittelbar neben der herzoglichen Residenzstadt Kleve $(1435)^{60}$. Wohl um Verwechslungen zu vermeiden, war das Bruderschaftszeichen anders gehalten; an einem wellenförmigen Band hingen links und rechts, etwa in Schlüsselbeinhöhe (und wohl auch hinten auf den Schulterblättern), etwa zollgroße Anhänger in Form eines Tau. Das „Kleinod“ bestand aus einer Krone, darunter einem Medaillon (in Größe eines Fünfpfennigstückes) mit einem Tau und darunter schließlich einem Löwen (Abb. 11) ${ }^{61}$. Ob dieses Tier in Erinnerung an die Antoniuslegende gewählt wurde, derzufolge zwei Löwen Antonius beim Begräbnis von Paul dem ersten Einsiedler geholfen haben ${ }^{62}$, oder als Symbol der Tapferkeit, muß offen bleiben. Im Gegensatz zu Barbefosse, wo die Aufnahme neuer Mitglieder vom gewählten Ordens- „König“, sieben Rittem und zwei Knappen entschieden wurde ${ }^{63}$, lag sie in Kleve allein im Ermessen des Herzogs; die Aufnahmegebühr betrug einheitlich drei rheinische Gulden ${ }^{64}$. Daß der sogenannte klevische Ritterorden vom heiligen Antonius tatsāchlich eine Antoniusbruderschaft war, ergibt sich aus der Feststellung, daß seine Angehörigen wie alle Mitglieder von Antoniuskonfraternitāten Anteil an den Messen, Gebeten und guten Werken des Antoniterordens hatten $^{65}$. Trotz der zusätzlichen Bestimmung, täglich fünf Paternoster und sechs Avemaria beten zu müssen, erfreute sich die neue Bruderschaft ausgesprochen großer Beliebtheit. Im Jahre 1454 sandte Herzog Johann I. von Kleve (1448-1481) den Antoniterpräzeptor Heinrich von Fley (1441-1470) auf Bitten des Ritters Nikolaus Rennouwe nach Dānemark, um dort nicht weniger als 50 Männern und Frauen „van guder ritterschap“ die vom Präzeptor geweihten „colliria of halsbant onss oirdens van sent Anthonius huys op den Houwe bij onser stat van Cleve“ als Zeichen der Aufnahme in die klevische Sozietät zu verleihen ${ }^{66}$.

Das Zeichen des heiligen Antonius und seines Ordens als eine besondere Auszeichnung für Edelleute, nicht nur in den ursprünglichen Verbreitungsgebieten Hennegau und Kleve, sondern weit darüber hinaus, das mußte andere Präzeptoren zur Nachahmung reizen, die hier eine neue Finanzquelle sprudeln sahen. Die Halskette mit dem

${ }^{60}$ Siehe hierzu jetzt die Zusammenfassung von Wilko Ossoba, Holger Kruse, St. Antonius (1420/ 1435), in: Holger Kruse, Werner Paravicini, Andreas Ranft (Hrsg.), Ritterorden und Adelsgesellschaften im spātmittelalterlichen Deutschland. Ein systematisches Verzeichnis (Kieler Werkstücke, Reihe D: Beiträge zur europäischen Geschichte des späten Mittelalters 1, Frankfurt am Main, Bern, New York, Paris 1991) 258-266.

${ }^{61}$ Ibid., $39 \mathrm{f}$.

62 Die Szene findet sich in der Legenda aurea in dem Kapitel „Von Sanct Paul, dem ersten Einsiedel" (Die Legenda aurea des Jacobus de Voragine aus dem Lateinischen übersetzt von Richard Benz (Heidelberg 1925) 112) und hatte Eingang in das ordensoffizielle Bildprogramm des Antoniuslebens (großes bemaltes Tuch zum Aufhängen in der Abteikirche Saint-Antoine, Prachtcodices) gefunden ( Rose Grabam, A Picture-book of the life of St. Anthony the Abbot, executed for the monastery of Saint-Antoine de Viennois in 1426, in: Archaeologia 83 (1933) 1-26, hier 4, 23, plate X, 4).

63 Noordeloos, Broederschappen, 494.

${ }^{64}$ Otto Eltermann, Der Clever Ritterorden St. Antonii und seine Wandlungen, in: Niederrheinischer Geschichts- und Altertumsfreund 11 (1913) 33 f., 39.

65 Ibid.

66 Theodor Ilgen, Die wiederaufgefundenen Registerbücher der Grafen und Herzöge von CleveMark (Mitteilungen der K. Preußischen Archivverwaltung 14, Leipzig 1909) 53f., Nr. 23. 
Tau und dem Glöckchen mußte noch begehrenswerter erscheinen, nachdem Jakob II. von Bourbon ("1370), Graf von La Marche (seit 1393) und König von Sizilien und Jerusalem (seit 1415) als großer Antoniusverehrer in seinem Testament von 1423 angeordnet hatte, daß seine Erben und Nachfolger stets die Potentia und das Glöckchen aus purem Gold am Hals tragen sollten ,in assumpte protectionis et defensionis huiusce ordinis signum ${ }^{467}$.

Um die Jahrhundertmitte - bereits 1457 wird wieder mit Heimfall an den Orden gerechnet $^{68}$-, dürfte durch einen Generalkapitelsbeschluß, vielleicht aber auch durch selbstāndiges Handeln deutscher Präzeptoren der Brauch eingeführt worden sein, im Gebiet des Reiches beliebig vielen mānnlichen wie weiblichen Adligen das „colare argenteum s. Anthonii cum campanella deaurata ${ }^{\text {"69 }}$ zu verleihen (Abb. 12 und 13). Sie konnten dieses Zeichen als Gegengabe für eine größere Spende erhalten ${ }^{70}$ oder auch kaufen: 1461 zahlt ein nicht näher bekannter Graf Wilhelm aus Süddeutschland für das noch nicht vergoldete "Kleinod“, wie es ordensamtlich hieß ${ }^{71}$, im Gewicht von $81 / 2$ Lot (ca. $125 \mathrm{Gramm}$ ) einen Preis von $3 \frac{1}{2} \mathrm{fl}, 8 \frac{1}{2} \mathrm{~B}$ und $3 \mathrm{hl}$. Dafür mußte er versprechen, „ut esset noster confrater et dum morietur promisit mittere (sc. colare) ad capellam s. Anthonii in Memmingen "72. Zum Doktor Promovierte waren den Adligen gleichgestellt. Am 13. Juni 1468 wurde Hartmann Schedel, ,arcium et medicinae doctor", in die Maastrichter Antoniusbruderschaft aufgenommen. Im Aufnahmeformular war ausdrücklich eine jährliche Spende an das dortige Antoniterhaus gefordert, was allgemein übliche Regel gewesen scin dürfte.

Wie überall, so wurde auch hier größter Wert auf die Rückgabe der kostbaren Bruderschaftszeichen an den ausgebenden Präzeptor gelegt ${ }^{73}$. In einem Beschluß des Generalkapitels von 1478 wurden sogar jene Präzeptoren mit der Strafe der Exkommunikation bedroht, die Bruderschaftsketten außerhalb ihres Zuständigkeitsbereiches ausgeben oder annehmen würden. Die Absichten des Herzogs von Kleve „und anderer

67 Falco, Compendium, fol. $91^{\mathrm{v}}$.

681456 wird dem Memminger Präzeptor die Antoniushalskette des + Claus Puchenbrunner zurückgegeben (Memmingen, Stiftungsarchiv 244/2, fol. 367), der das Kastenamt des Augsburger Domkapitels in Straubing innehatte (München, Hauptstaatsarchiv, Augsburg, Domkapitel 1676). Zum Besitz des Augsburger Domkapitels in Straubing seit 1029 vgl. Friedrich Zoepfl, Das Bistum Augsburg und seine Bischöfe im Mittelalter (München, Augsburg 1955) 88.

69 Siehe Anm. 70.

701458 X 13: der Memminger Präzeptor Petrus Mitte de Caprariis (Pierre Mitte de Chevriéres) schickt der Herrin von Waldegg (an der Iller, $11 \mathrm{~km}$ südlich Memmingen) als Dank für vier gute Schweine das ,colare argenteum s. Anthonii cum campanella deaurata" (Memmingen, Stiftungsarchiv 244/2, fol. 49ๆ). Die Herrschaft Waldegg war seit $1403 \mathrm{im}$ Besitz des Memminger Geschlechts Mangold (Franz Ludwig Baumann, Geschichte des Allgäus 2 (Kempten 1884) 142, 587). Zur Familie Mangold siehe auch die kurze Notiz bei Raimund Eirich, Memmingens Wirtschaft und Patriziat von 1347 bis 1551 (Weißenhorn 1971) $291 \mathrm{f}$.

7 So schon 1461 XI 26 (München, Hauptstaatsarchiv, Memmingen, Antoniter). Vgl. auch Anm. 78).

721461 III 21 (Memmingen, Stiftungsarchiv 244/2, fol. $106^{\vee}$ ).

${ }^{3}$ Der Text aus Clm 215, fol. $44^{r}$ über die Bruderschaft und ihre Zeichen ist vollstāndig abgedruckt bei Pieter Noordeloos, Antoniana, in: Archief voor de geschiedenis van de katholieke kerk in Nederland 1 (1959) 27-107, hier 104. Jene Statuten von Barbefosse, kürzer und wohl jünger als die in Anm. 55 genannten, die ebenfalls Doktoren zuließen, siehe ibid. $100 \mathrm{f}$. 
Fürsten und Herren, die Kirchen unseres Ordens gegründet haben“, sollten jedoch von dieser Anordnung unberührt bleiben ${ }^{74}$.

Die Einbindung des Adels in den Frömmigkeitsbereich, der Reservat der Antoniter war, dauerte nicht sehr lange. Als erste scheint die klevische Bruderschaft verschwunden zu sein; 1483 wird sie zum letzten Mal erwähnt ${ }^{75}$. Entgegen anderslautenden Behauptungen ${ }^{76}$ ist von Antoniuskollaren und deren Rückgabe an das Antoniterhaus in Barbefosse noch in der zweiten Hälfte des Jahrhunderts, 1470 und 1476, die Rede ${ }^{77}$. Die allgemein ausgegebenen Adelsketten sind noch länger nachzuweisen. „Was klainat ... von Edeln leütten gefallen, die Sant Anthonis gesellschaft tragen“, müssen gemäß Verträgen von 1503 und 1506 von den Balleipächtern an den verpachtenden Memminger Präzeptor ausgefolgt werden ${ }^{78}$.

Damit befinden wir uns bereits an der Schwelle der Reformation, in deren Folge der von den Antonitern gepflegte und eifersüchtig gehütete Antoniuskult rasch zusammenbrach. Aus den vereinzelten Stimmen der Kritik, wie sie im Laufe der Jahrhunderte immer wieder ertönt waren, auch aus dem Munde so kirchlich gesinnter Mānner wie des Panormitanus und des Nikolaus von Kues, war nun ein mächtiger Chor geworden, der mit Argumenten der Vernunft und des biblisch fundierten Glaubens gegen ihn kämpfte. Für einen Straf- und Racheheiligen war da kein Platz mehr. Auch in den altglāubig gebliebenen Territorien verschwanden die Antoniusschweine. Das Konzil von Trient untersagte 1546 und nochmals 1562 die Sammelfahrten ${ }^{79}$. Das Tau, zu Anfang des Jahrhunderts noch gemeinsames Ehrenzeichen von Fürsten und Bauern, von stolzen Rittern und armen Krüppeln, verschwand für immer aus der Öffentlichkeit.

74 Liber Statutorum, fol. 199.

5 Gorissen, Ritterorden, 44.

76 Gorissen, meint, daß der Orden bereits „1436 zu verlöschen begann“ ibid., 34 .

77 Léopold Devillers, Chartes du Chapitre de Sainte-Wandru de Mons 3 (Bruxelles 1908) 344, Nr. 1394; 383, Nr. 1451.

781503 I 17 und 1506 III 9 (Memmingen, Stadtarchiv 356/1).

791546 VI 17 und 1562 VII 16 (Conciliorum Oecumenicorum Decreta curantibus Josepbo Alberigo (et aliis) (Bologna ${ }^{3} 1973$ ) 670, $731 \mathrm{f}$. 


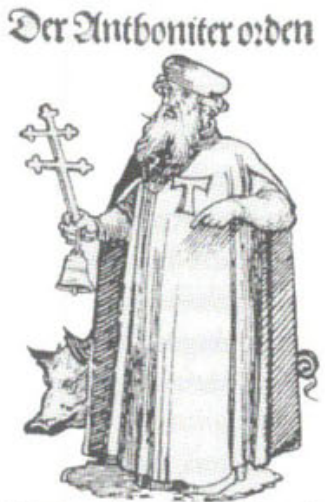

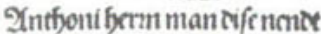
Tnalle lanterinan fic itol fmot Tas nuadte ir ftetteg tenninim Das arm nold fic idsontidid verfürm S?it trautung fand Xntbonipern

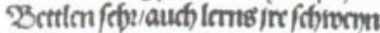

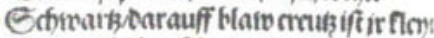

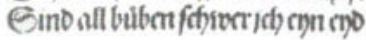
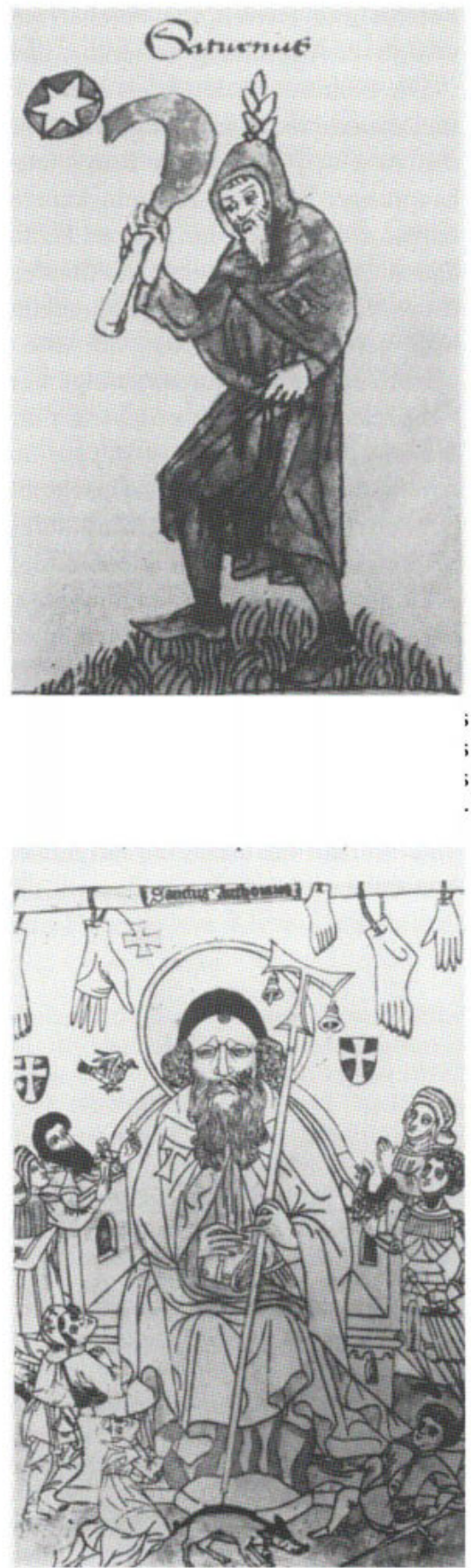

$A b b .4$ Antonius, von Gesunden und Kranken angerufen. Holzschnitt, Ende des 15. Jahrhunderts (München, Staatliche Graphische Sammlung, Nr. 118241). 


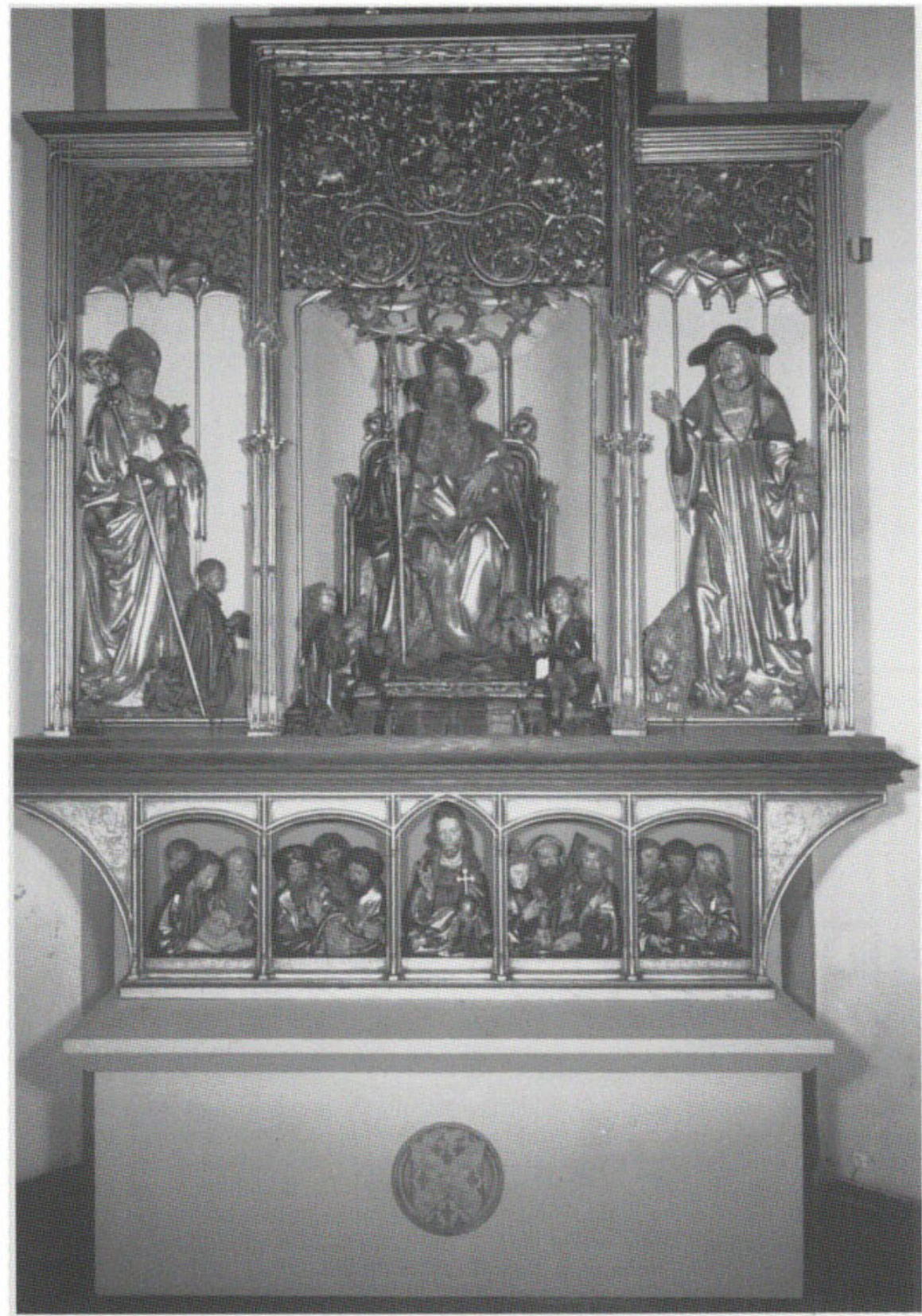

Abb. 5 Isenheimer Altar. Niclaus von Hagenau, um 1490 (Colmar, Musée Unterlinden). 

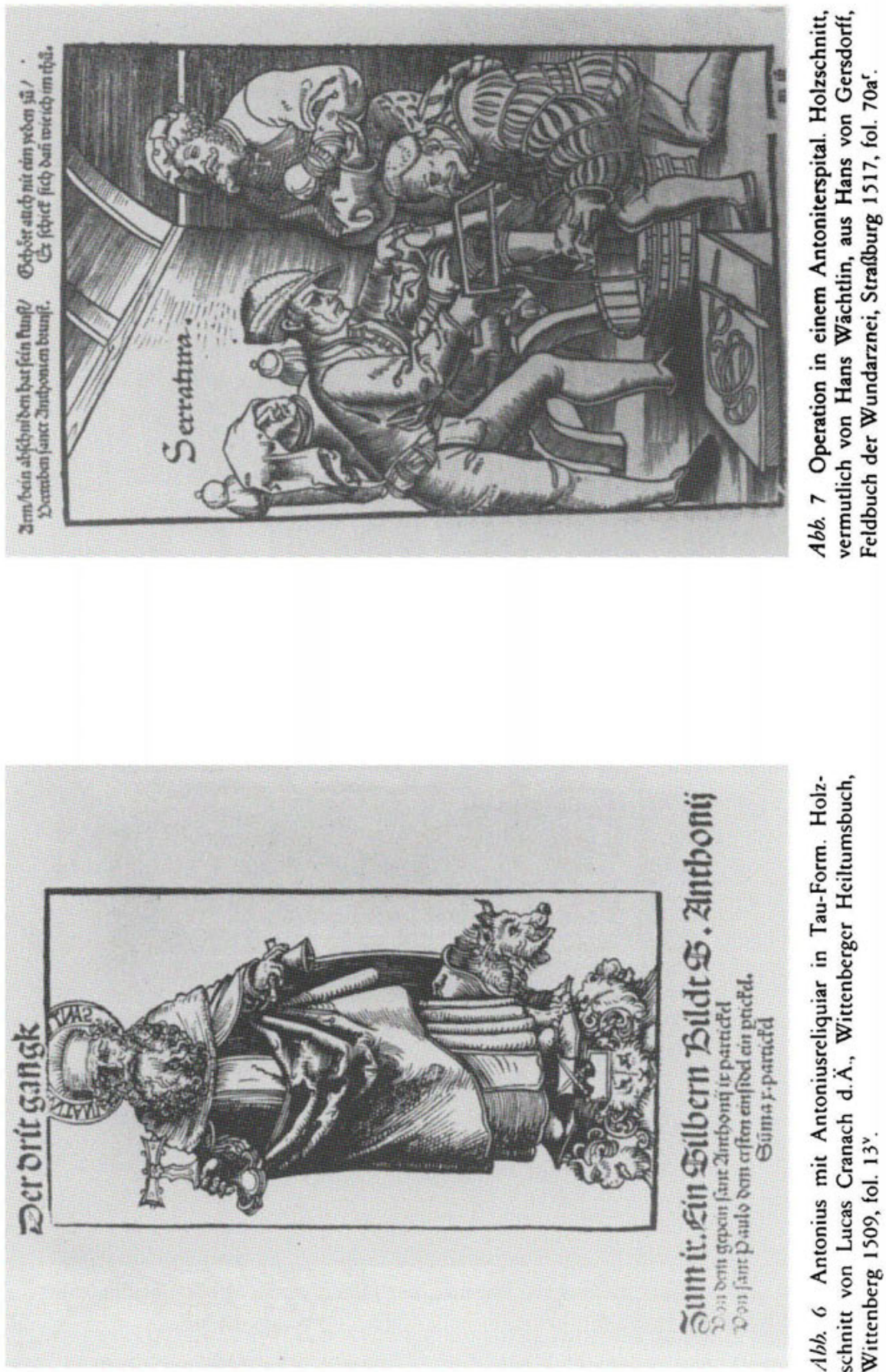


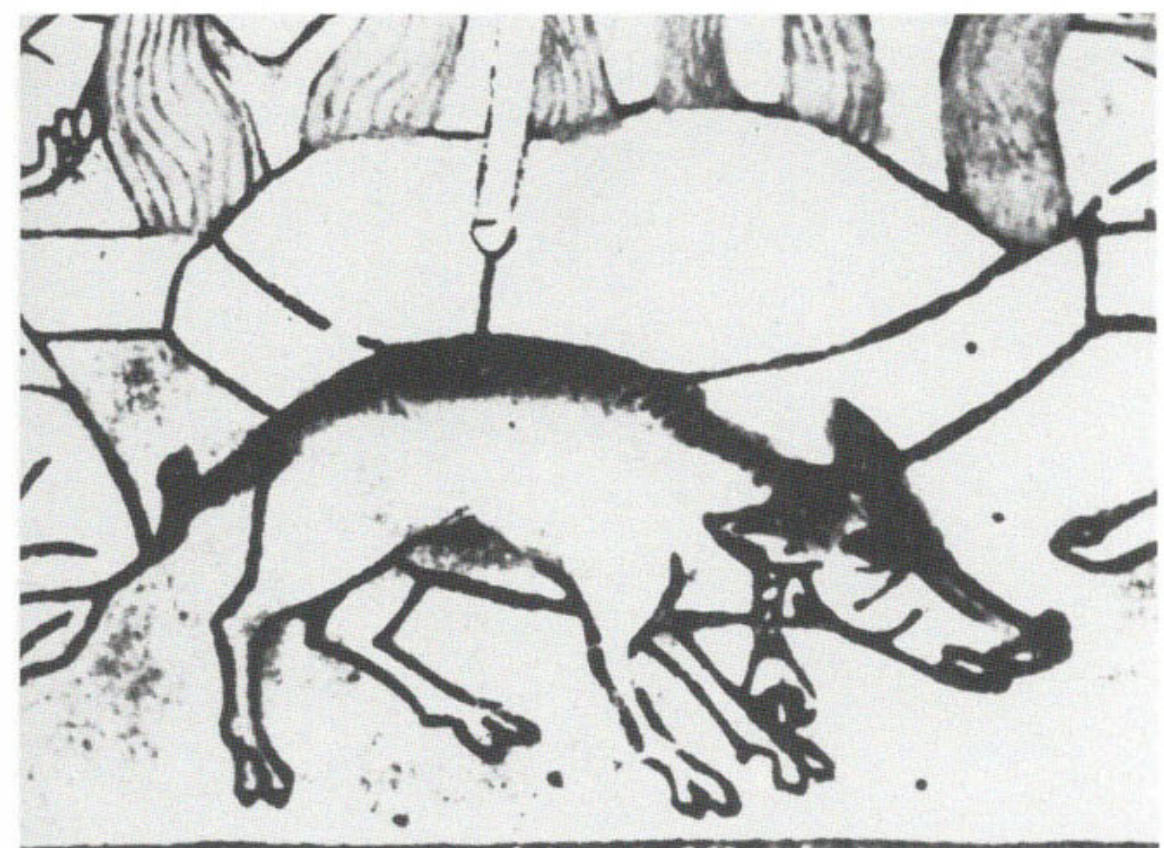

Abb. 8 Antoniusschwein mit Glöckchen am Hals. Ausschnitt aus Abb. 4 .

Abb. 9 Antoniusschwein mit Glöckchen am Ohr. Ausschnitt aus Holzschnitt, um 1420 (München, Staatliche Graphische Sammlung, Nr. 118261).

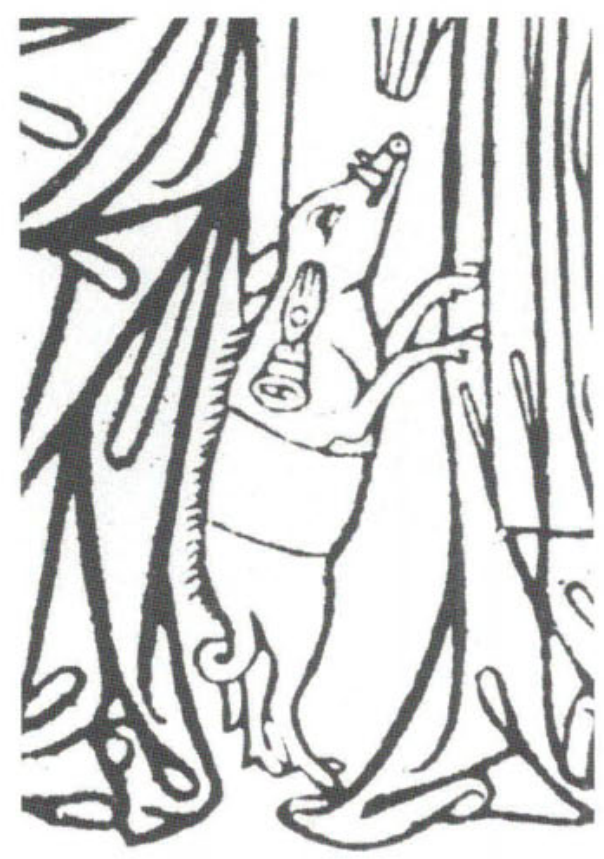




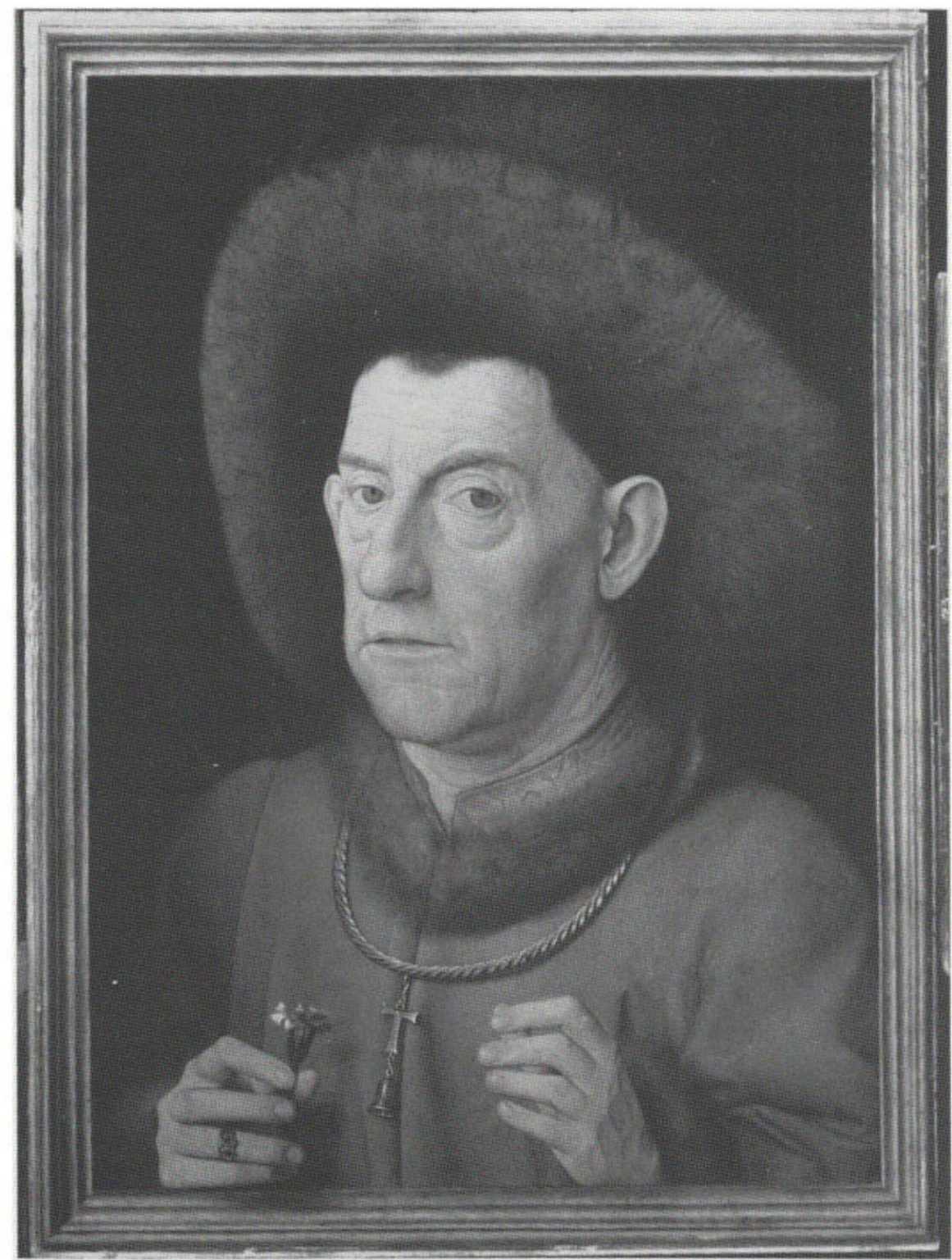

Abb. 10 Der Mann mit den Nelken (Edelknappe aus der Antoniusbruderschaft von Barbefosse?). Gemälde nach Jan van Eyck, 15. Jahrhundert (Berlin, Staatliche Museen Preußischer Kulturbesitz). 


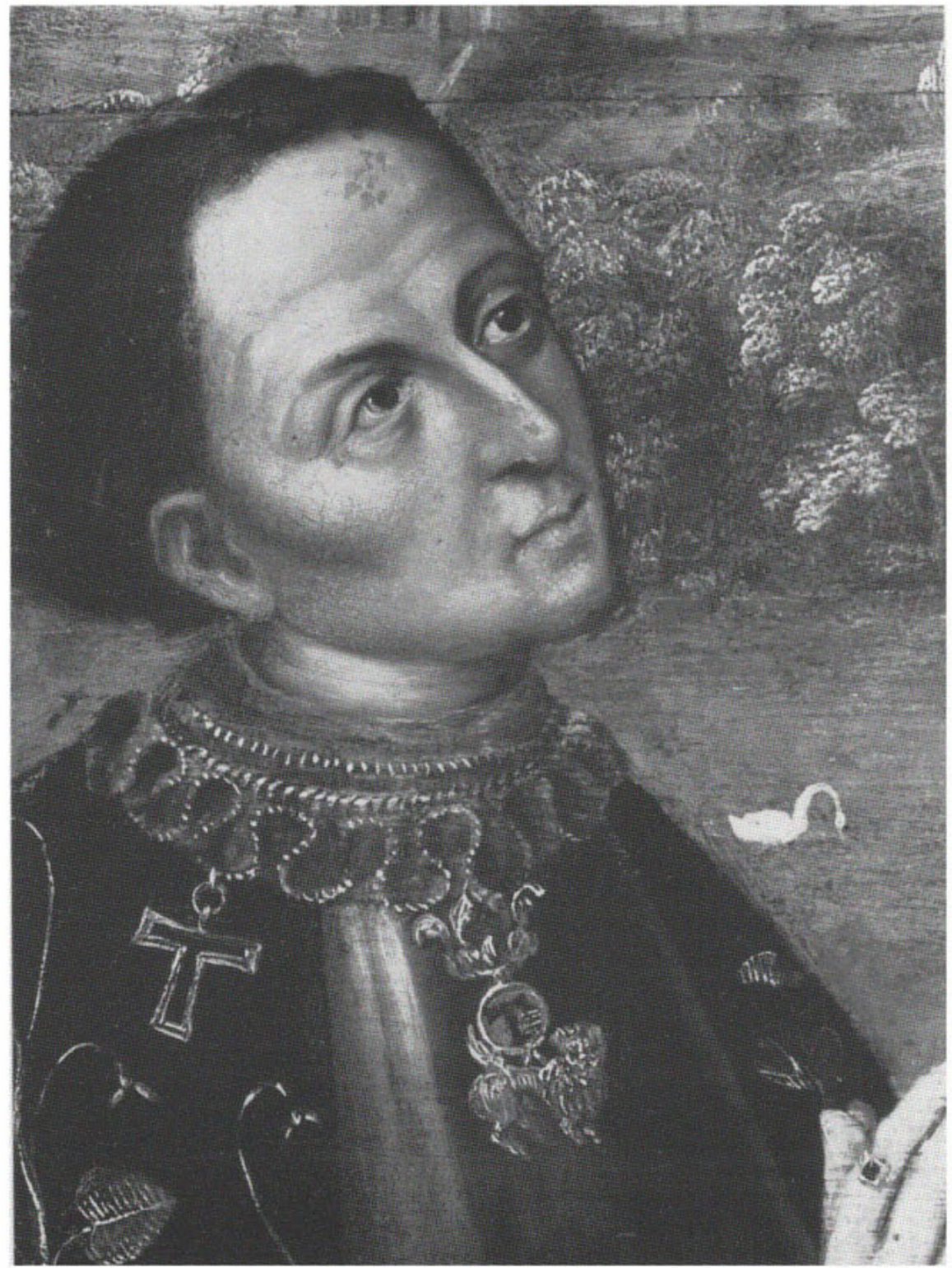

Abb. 11 Herzog Adolf II. von Kleve mit Antoniusordenscollier. Gemälde (Kopie nach einem zeitgenössischen Original) um 1650 durch Henrik Veltman (Kleve, Rathaus). 
Abb. 12 Adlige Dame mit Antoniusordenscollier. Kupferstich, Ausschnitt aus Der große Liebesgarten, Der Meister der Liebesgärten, um 1450 (Berlin, Staatliche Museen Preußischer Kulturbesitz, Kupferstichkabinett).

Abb. 13 Adliger Herr mit Antoniusordenscollier im Frauenhaus. Kupferstich, Meister mit den Bandrollen, ca. 14601470 (Wien, Graphische Sammlung Albertina).

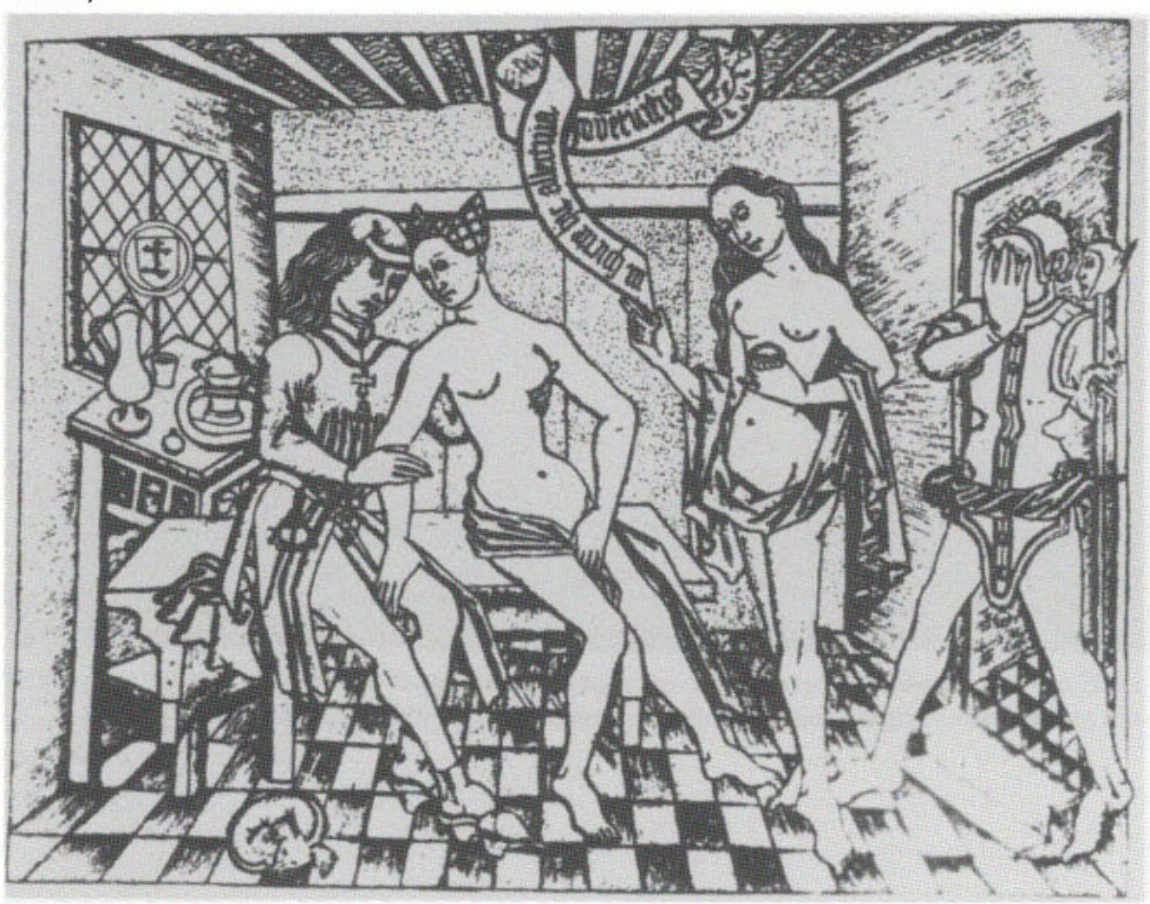

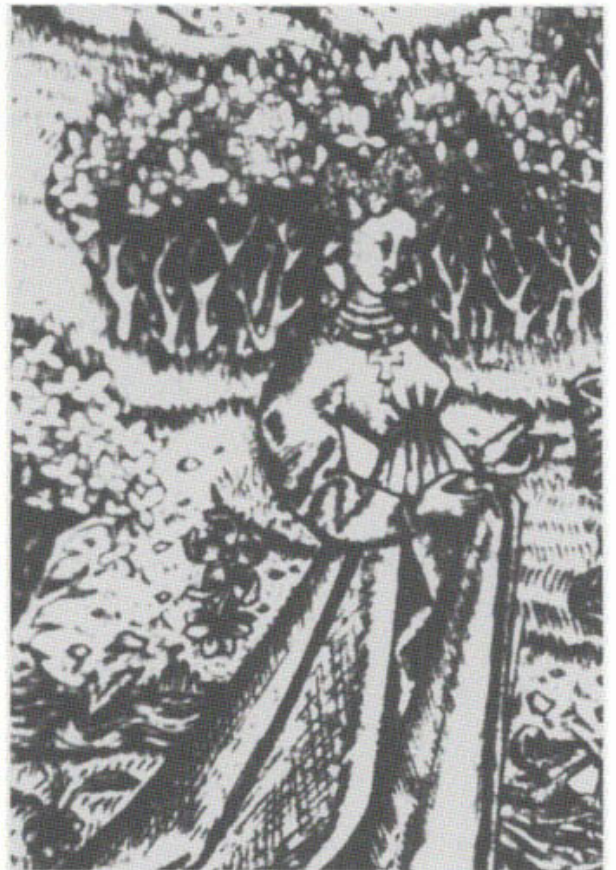

